\title{
Research on the Subjective Quantity of Modern Chinese Language Formula "There Is No (X) More W than Y” (“没有 $(X)$ 比Y更W的(了)”)
}

\author{
Ying Huang \\ Hebei University, Baoding, China \\ Email: hyingmm@126.com
}

How to cite this paper: Huang, Y. (2018). Research on the Subjective Quantity of Modern Chinese Language Formula "There Is No $(\mathrm{X})$ More W than $\mathrm{Y}$ ” (“没有 $(\mathrm{X})$ 比 $\mathrm{Y}$ 更W的(了)"). Open Journal of Modern Linguistics, 8, 17-22.

https://doi.org/10.4236/ojml.2018.82003

Received: March 26, 2018

Accepted: April 24, 2018

Published: April 27, 2018

Copyright $\odot 2018$ by author and Scientific Research Publishing Inc. This work is licensed under the Creative Commons Attribution International License (CC BY 4.0).

http://creativecommons.org/licenses/by/4.0/

\begin{abstract}
"Subjective quality" is the specific embodiment of language subjectivity in a quantitative category. "There is No $(\mathrm{X})$ more $\mathrm{W}$ than $\mathrm{Y}$ " is one of the more common structures in modern spoken Chinese, and which has strong subjectivity and large subjective. The paper analyzed subjective construction from subjectivity, inscape, subjective representation and other aspects.
\end{abstract}

\section{Keywords}

Subjective Quantity, "There Is No (X) More W than Y”, Language Formula, Construction Elements

\section{Research Generalization to "Subjective Quantity"}

"Subjective quantity" is the specific embodiment of language subjectivity in a quantitative category, which is a kind of quantity with subjective feeling, attitude and assessment meaning. Outside of China, research carried out on this subject is early, and subjectivity and subjectivism research became a hot point for linguistic research until Langacker (1990), Traugott (1995) and Lyons (1995). Domestic attention to the quantitative category is long-standing, including Gao Mingkai (1948), Wang Li (1954), Zhao Yuanren (1979), Zhu Dexi (1980), Lu Jianming (1989). The first one who examined "subjective quantity" was Ma Zhen (1981), but Chen Xiaohe (1994) proposed conception of "subjective quantity" at the very first time. Ma Zhen proposed: in modern Chinese, there are parts of adverbs which modify quantifiers and indicate one's opinion and attitude towards a certain quantity. Like “he eaten five only” (“他吃了才五个”), that just narrates the quantity he has eaten objectively.) If "just" is added before 
"five," which means "he just eaten five", this is speaker's subjective attitude to that quantity and means the five is not too many in the opinion of the speaker." Ma Zhen also classified adverbs which directly modify quantity structure into "enough", "many", "equivalent", "appraise", "real quantity", "total" and made complete analysis of grammar and semanteme. The adverbs like "many" and "few" are "subjective mass" and "subjective small quantity" proposed by Chen Wen, whose work discussed adverbs related to subjective quantity and means of expressing subjective quantity as stress, statement label designator, suffix, which has had pioneering significance.

Li Yuming (1997, 1999a, 1999b) and Li Xishan (2003) further developed the framework of the quantitative category system: material quantity, time quantity, movement quantity, order quantity and linguistic potential; they made deep and comprehensive research on expression means of subjective quantity. Zhang Guoxian (1996), Zhang Yisheng (1990), Cao Xiuling (2005), Li Jinrong (2007), Wen Suolin (2012) also made relevant research on problems of Chinese subjective quantity, and this research pushed research on subjective quantity a big step whatever in depth or breadth.

The formula "there is no $(\mathrm{X})$ more $\mathrm{W}$ than $\mathrm{Y}$ " is a negative comparative construction, which means reaching comparison by negative form. As to the construction formula, Li Xiao (2014) and Shi Mengjie (2005) made relevant research.

\section{Subjectivity of "There Is No (X) More W than Y"}

Subjectivity is embodied in the vision and emotion of the speaker.

\subsection{Vision of the Speaker}

"Vision" is the speaker's observation vision to objective status or starting point to tell objective status (Shen Jiaxuan, 2011). The angles of different people looking at the same thing will produce different emotional attitudes or realizations. "It's like a range when you look at the mountain from the front. But it's like a peak when you look at it sideways. The mountain shows its different features in different levels near and far". But different "vision" is for our different emotional attitudes or realizations of or toward things, hence it is said that vision, emotion and realization affect themselves mutually. The research on "vision" can be realized by analyzing grammar form.

1) On such a day, there is nothing more comfortable than sleeping. (这样的 天，没有比睡觉更舒服的。)

In example 1), the speaker appraises "there is nothing more comfortable than sleeping on such a day," which is to character degree of the thing. In fact, "there is nothing more comfortable than sleeping" is the speaker's subjective judgement with strong subjectivity, but there hasn't appear "I think" or "I believe", which is because the judgement is made at the angle of the periphery and the expressed meaning is obvious, hence the receiver's acceptance to the information given by speaker is increased. 
Therefore, the speaker's vision exists in "there is nothing (X) more $\mathrm{W}$ than $\mathrm{Y}$ ", and most of it is the speaker's judgement at the outer angle with intensive subjectivity.

\subsection{The Speaker's Emotion}

In abroad sense, the word of "emotion" includes emotion, mood, intention, attitude and so forth. The first two are referential function and expressive function, and the third kind is emotion when people use language to express a proposition there will have emotion. The expressed emotion of "there is no (X) more W than $\mathrm{Y}$ " has intensive subjective emotion, which is brought by complete construction formula.

2) He is a kind person. (他是个善良的人。)

3) There is no man more kind than him. (没有比他更善良的人了。)

Example 2) stated an objective truth that "What kind of men he is? He is a kind man". Example 3) used our construction formula and expressed meaning includes speaker's trust and appreciation to "him" except "he is the kindest man". The deeper research on "emotion" is "pragmatic empathy". In language interaction, the communicative parties can imagine and understand opposite intention and encode and decode at opposite position. Successful "pragmatic empathy" not only can make interaction in process but can deepen mutual understanding between speaker and listener and make interaction develop in a favorable direction. For instance: when someone says, "there is no more kind man than him", the listener is aware that the speaker very much appreciates "him", and the listener should consider the speaker's feeling if he or she wishes to continue the topic, so the listener shouldn't say "he is not kind".

\section{Construction Elements of "There Is Nothing (X) More W than Y"}

\subsection{Negative Adverb "Nothing"}

The negative adverb "nothing" in "there is nothing $(\mathrm{X})$ more $\mathrm{W}$ than $\mathrm{Y}$ " construction formula is simple but vital, the complete meaning of construction formula will be changed thoroughly if there is no "nothing" present. As 1), it will become "the one while more kind than him" if "nothing" is removed, the meaning is converse with original meaning of construction formula, meanwhile, there should fill out contrasting preceding before the sentence. Thus "nothing" is vital in construction formula. There are few situations of "no" replacing "nothing", and there are more adverbs "again", "no longer" for strengthening comparison in front. As: 4) there is no more serious thing than this. (再没比这件事更严重的了。)

\subsection{Limiting the Scope of Comparison}

$\mathrm{X}$ can appear in construction formula or not, and X has great relation with "of" and "over" which is behind construction. Construction meaning negated X's real existence, $\mathrm{X}$ will can be exhibited in language is for predominating non-existent 
$\mathrm{X}$ and emphasize "Y is more $\mathrm{W}$ ". for instance, 5) "there is nothing more happy than grasping bad man. (没有什么比抓住坏人更痛快。)

The construction got rid of possibility of thing or phenomenon of "more $\mathrm{W}$ than Y", therefore, it will limited by cycle semantic condition in its semanteme if there appear $\mathrm{X}$ in construction, which means the role of $\mathrm{X}$ is to delimit comparison range with Y. X can be spreading as "what", "any", "where", "which place", "who" and so forth.

\subsection{Comparison Term and Comparison Focus W}

$\mathrm{Y}$ as a comparison term is very free, but $\mathrm{Y}$ is affiliated with $\mathrm{X}$ in semantic scope, and $\mathrm{W}$ has the relation of nature and attribute, $\mathrm{W}$ is the nature of $\mathrm{Y}$ and is restricted by Y. As in example 5) of "grasp bad man\} has feature and attribute of "happy" while the ingredient of modifying $\mathrm{Y}$. A certain aspect of $\mathrm{W}$ as $\mathrm{X}$ to compare with $\mathrm{Y}$ is the focus of their comparison, often used as an adjective or predicate phrase. [9]

\subsection{Evaluative Adverb "More"}

"More" has evaluative meaning in the construction, and there are situations where "again" and "also" are used in the construction, as in examples 6), 7), but the uses are limited and the construction is prone to the adverb "more".

6) There is nothing more forwarding than honor! (真是没有比荣誉再令人向 往的了!)

7) There is nothing happier than this. (没有比这还快活的了。)

The adverb "more" ("again" and "also") gives a degree of meaning to $\mathrm{Y}$ to some degree, and the inner meaning of this degree can reach the limit after negative comparison, hence there produced a great deal of subjective degree. If the construction removes "more" ("again" and "also") can be tenable in sentence structure, but will lose the color of subjective appraisal.

\section{Subjective Quantity Performance of "There Is No (X) More W than Y"}

"Subjective quantity" is specific embodiment of subjectivity of language in quantitative category. Human beings' recognition is not a direct reflection of the world quantity passively but rather with subjective feeling, attitude and appraisal, making the objective quantity possess a degree of subjectivity.

Modern Chinese adjectives have a degree of quantitative property, such as: state adjective and nature adjective have difference in quantity degree. Due to quantitative property of state adjective is stronger, they themselves have included ingredient of expressing degree, hence they cannot be modified by degree adverbs, as "snow-white and ice-cold" have strong quantitative property with meaning of "very while and very cold", hence state adjective cannot enter into the construction we research ( $\mathrm{W}$ is modified by adverb "more"), only part of nature adjectives can serve as $\mathrm{W}$, these nature adjectives have quantitative prop- 
erty, their quantitative property is not too strong but diffused and invisible. Except nature adjectives, psychological verbs, volitive auxiliaries, with or without verbs, some double syllable literal verbs and some predicate nouns can serve as $\mathrm{W}$, they are all have character meaning which characterized in quantitative property, but their quantitative property features are diffused and invisible like quantitative property features of nature adjectives.

Quantitative property of "there is nothing $(\mathrm{X})$ more $\mathrm{W}$ than $\mathrm{Y}^{\text {" is implicated }}$ in variable $\mathrm{Y}$, its subjective mass is performed by adverb markers, sentence end mark and complete construction of the whole negative comparison, besides, potential intonation also promotes formulation of subjective mass. Subjective mass meaning of construction is embodied by the complete construction, various structural elements play the role in promoting produce of subjective mass meaning, superposition of negative adverbs and comparison structure makes $\mathrm{Y}$ with degree meaning performs meaning of subjective host by reverse negation.

The understanding to counter quantity is different from different people, the linguistic basis of subjective host meaning of construction is comparison meaning of the construction and negative existential meaning produced by negative adverbs "nothing" acting on after construction. But in the final analysis, subjective mass of construction is based on the speaker's presupposition. Speaker and listener have a degree of recognition basis to the compared thing, hence $\mathrm{X}, \mathrm{Y}, \mathrm{Z}$ appeared in construction have a familiarity and typicalness in a certain semantic domains, we call it semantic presupposition; or three parties have an account in language environment and we call it contextual presupposition; therefore, construction can make semanteme clean only when apply it in larger environment, subjectivity will be more predominant whatever in any presupposition if without negative function of "nothing" and expressed speaker's attitude and opinion to quantity, even speaker's exaggerated emotional color.

\section{References}

Cao, X. L. (2005). Study on "Even...... All/Also..." Sentence Pattern. Linguistic Research, 1, 17-20.

Chen, X. H. (1994). Preliminary Study on Subjective Quantity-On the Adverb "Just", "CAI", “all”. World Chinese Language Teaching, 4, 18-24.

Gao, M. K. (1948). Chinese Grammar. Shanghai: Shanghai Kai Ming Bookstore.

Langacker, R. M. (1990). Subjectification. Cognitive Linguistics, 1, 5-38. https://doi.org/10.1515/cogl.1990.1.1.5

Li, J. R. (2007). Some Problems in the Research of Chinese Quantity Category. Journal of Ningxia University, 5, 1-7.

Li, M. Y. (1997). The Cause of Subjective Measurement. Chinese Learning, 5, 3-7.

Li, S. X. (2003). Research on the Expression of "Subjective Quantity" in Chinese. Ph.D. Thesis, Beijing: Chinese Academy of Social Sciences.

Li, X. (2014). "No (A) More $Y$ than $X$ ” Syntax Analysis. Master's Thesis, Guilin: Guangxi Normal University.

Li, Y. M. (1999a). Structure of “一 V... 数量” and Subjective Large Quantity. Chinese Language Learning, 4, 2-6. 
Li, Y. M. (1999b). Quantitative Words and Subjective Quantities. Journal of Central China Normal University (Humanities and Social Sciences), 6, 90-97.

Lu, J. M. (1989). Measuring Adjectives. Language Teaching and Research, 3, 46-59.

Lyons, J. (1995). Linguistics Semantics: An Introduction. Cambridge: Cambridge University Press. https://doi.org/10.1017/CBO9780511810213

Ma, Z. (1981). The Adverb of Modification of Quantitative Words. Language Teaching and Research, No. 1, 53-60.

Shen, J. X. (2001). The "Subjectivity" and "Subjectivization" of Language. Foreign Language Teaching and Research, 4, 268-275, 320.

Shi, M. J. (2005). "No More Y than X (a)" Research on the Structure Type of the Subjectivity and Subjective Quantity. Modern Chinese Language Study Edition, 2, 70-74.

Traugott, E. C. (1995). Subjectification in Grammaticalization. Cambridge: Cambridge University Press.

Wang, L. (1954). Author of Chinese Grammar Theory. Beijing: Zhonghua Publishing House,

Wen, S. L. (2012). The Quantitative Expression of Discourse Subjectivity. Language Studies, 32, 72-80.

Zhang, G. X. (1996). The Quantity of Adjectives. Chinese Teaching In the World, 4, $35-44$.

Zhang, Y. S. (1990). A Synchronic Comparison of Modern Chinese Adverbs "Cai". Journal of Shanghai Normal University, 3, 45-50.

Zhao, Y. R. (1979). Spoken Chinese Grammar. Beijing: Commercial Press.

Zhu, D. X. (1980). Study on Modern Chinese Grammar. Beijing: Commercial Press. 